\title{
Reaction kinetics of mechanically activated cordierite-based ceramics studied via DTA
}

\author{
Nina Obradović ${ }^{1} \cdot$ Nataša Đorđević $^{2} \cdot$ Suzana Filipović ${ }^{1} \cdot$ Smilja Marković $^{1} \cdot$ \\ Darko Kosanović $^{1} \cdot$ Miodrag Mitrić $^{3} \cdot$ Vladimir Pavlović $^{1}$
}

Received: 19 August 2015/ Accepted: 24 October 2015/Published online: 27 November 2015

(C) Akadémiai Kiadó, Budapest, Hungary 2015

\begin{abstract}
Since cordierite, $2 \mathrm{MgO} \cdot 2 \mathrm{Al}_{2} \mathrm{O}_{3} \cdot 5 \mathrm{SiO}_{2}$ (MAS), is a very useful high-temperature ceramic material, it is important to decrease its sintering temperature. In order to accelerate the process of sintering, 5.00 mass $\% \mathrm{MoO}_{3}$ was added to the starting mixtures. The mechanical activation of the starting mixtures was performed in a high-energy ball mill in time intervals from 0 to $160 \mathrm{~min}$. After the activation, starting mixtures were sintered at $1300{ }^{\circ} \mathrm{C}$ for $2 \mathrm{~h}$. In order to determine the impact of mechanical activation on particle size distribution and powders morphology, the mechanically treated powders were characterized by a laser light-scattering particle size analyzer and scanning electron microscopy. The phase composition of the starting mixtures and sintered samples was analyzed by the $\mathrm{X}$-ray diffraction method. In order to determine temperature intervals of chemical reactions and phase transitions, differential thermal analyses (DTA) and thermo-gravimetric analysis were used. Kissinger's equation was employed to calculate apparent activation energies of various processes that occur within the system during heating. Based on the obtained DTA results, it was established that mechanical activation along with $\mathrm{MoO}_{3}$ additive has influence on sintering temperature which was decreased for more than $100{ }^{\circ} \mathrm{C}$, comparing to the literature data.
\end{abstract}

Nina Obradović

nina.obradovic@itn.sanu.ac.rs

1 Institute of Technical Sciences of SASA, Knez Mihailova 35/IV, Belgrade 11000, Serbia

2 Institute for Technology of Nuclear and Other Mineral Raw Materials, Bulevar Franse d'Eperea 86, Belgrade 11000, Serbia

3 Vinča Institute of Nuclear Sciences, University of Belgrade, Mike Alasa 12-14, Belgrade 11000, Serbia
Keywords Mechanical activation $\cdot \mathrm{DTA}-\mathrm{TG} \cdot$ Sintering $\cdot$ Kinetics · Cordierite

\section{Introduction}

Cordierite-based ceramics $\left(2 \mathrm{MgO} \cdot 2 \mathrm{Al}_{2} \mathrm{O}_{3} \cdot 5 \mathrm{SiO}_{2}\right)$ are widely applied in many fields due to their mechanical as well as electrical properties. Very low-temperature thermal expansion coefficient $\left(20 \times 10^{-7}{ }^{\circ} \mathrm{C}^{-1}\right)$ makes this material applicable in devices exposed to sudden temperature changes, such as heating element supports, refractory ceramics for furnaces, oven-ware [1-7]. Low value of dielectric constant $(\sim 5)$ and high specific resistivity nominates this ceramic for application in electronics as an insulating material for devices operating in high frequencies, filters, multilayer circuit boards, etc. [8].

There are a few known approaches to produce cordierite ceramics, such as sol-gel method [2,9], preparation from preceramic risen [10], but the most often is solid-state reaction due to its simplicity, inexpensiveness as well as production of larger amount of products necessarily for detailed investigation or commercial processing [8, 11-13]. In order to overcome kinetic/diffusion constraints, deriving from distance of particles in powders, which is common in solid-state reaction and require high synthesis temperatures, mechanochemical activation is very useful method. Process of activation increase the diffusion rates of components in mixture across phase boundaries, leading to accelerated reaction $[8,14]$. During mechanical treatment, several processes occur: attrition of starting material, crystal lattice destruction, introduction of defects, etc. All mentioned processes increase the chance that during heating, synthesis and/or sintering process could be observed at lower temperatures than usual [15]. 
Beside mechanical activation, additives addition is often used method for improvement in reaction in powders mixtures. There are many efforts of improvement in solidstate reaction in cordierite, which reduces sintering temperatures by adding different kind of functional additives: yttria-stabilized zirconia, ceria, $\mathrm{B}_{2} \mathrm{O}_{3}, \mathrm{P}_{2} \mathrm{O}_{5}, 2 \mathrm{MgO} \cdot \mathrm{B}_{2} \mathrm{O}_{3}$, etc. $[8,9,16]$.

Influence of combined effect of mechanical activation and additives is interesting for investigation. In this paper, simultaneous effects of mechanical treatment and sintering additives were investigated through monitoring reaction kinetics of mechanically activated cordierite-based ceramics, doped with $\mathrm{MoO}_{3}$, via DTA.

\section{Experimental}

Mixtures of $\mathrm{MgO}, \mathrm{Al}_{2} \mathrm{O}_{3}, \mathrm{SiO}_{2}$ and $\mathrm{MoO}_{3}$ (all $99 \%$ Sigma-Aldrich) were used in these experiments. The mixtures of $\mathrm{MgO}+\mathrm{Al}_{2} \mathrm{O}_{3}+\mathrm{SiO}_{2}$ in the 2:2:5 molar ratio, with the addition of 5.00 mass $\% \mathrm{MoO}_{3}$, were mechanically activated by grinding in a high-energy planetary ball mill. $\mathrm{ZrO}_{2}$ vessels and balls were used with the powder-to-balls mass ratio of 1:40. The milling process was performed in air for 10, 40, 80 and $160 \mathrm{~min}$. The samples were denoted as C-1-C-5 (C-1 for non-activated mixture, C-5 for $160 \mathrm{~min}$ of activation process).

The X-ray powder diffraction patterns were obtained using a Philips PW-1050 diffractometer with $\lambda \mathrm{Cu}-\mathrm{K}_{\alpha}$ radiation and a step/time scan mode of $0.05^{\circ} \mathrm{s}^{-1}$. The measurements were taken on room temperature in air atmosphere.

The average particle size and particle size distribution were determined by a laser light-scattering particle size analyzer (PSA). The used instrument was Mastersizer 2000 (Malvern Instruments Ltd., UK) particle size analyzer based on laser diffraction, covering the particle size range of 0.02-2000 $\mu \mathrm{m}$. For the PSA measurements, the powders were dispersed in distilled water, in ultrasonic bath (lowintensity ultrasound, at a frequency of $40 \mathrm{kHz}$ and power of $50 \mathrm{~W}$ ), for $5 \mathrm{~min}$.

The morphology of the powders obtained after sintering was characterized by scanning electron microscopy (JEOL JSM-6390 LV). The pellets were cracked and covered with gold in order to perform these measurements.

The thermal behavior was determined by simultaneous TG-DTA (Setsys, SETARAM Instrumentation, Caluire, France) in the temperature range between 25 and $1400{ }^{\circ} \mathrm{C}$ under the air flow of $20 \mathrm{~mL} \mathrm{~min}^{-1}$, in an $\mathrm{Al}_{2} \mathrm{O}_{3}$ pan. Experiments were done by heating rates of 5, 10, 20 and $30{ }^{\circ} \mathrm{C} \mathrm{min}{ }^{-1}$. Kissinger's equation was used to calculate activation energies of processes that occur within the system while heating.
The binder-free powders were compacted using the uniaxial double-action pressing process in an 8-mm-diameter tool (Hydraulic press RING, P-14, VEB THURINGER). The applied pressure was $392 \mathrm{MPa}$, and an amount of $0.3 \mathrm{~g}$ of powders was used for each pressed sample. The compacts were placed in an alumna boat and heated in a tube furnace (Lenton Thermal Design Typ 1600). The compacts were sintered isothermally at $1300{ }^{\circ} \mathrm{C}$ in air atmosphere for $120 \mathrm{~min}$; the heating rate was $10{ }^{\circ} \mathrm{C} \mathrm{min}{ }^{-1}$. The density of specimens was calculated from the precise measurements of their diameter, thickness and mass.

\section{Results and discussion}

Diffraction pattern for $\mathrm{C}-1$ mixture showed the presence of starting components $\left[\mathrm{Mg}(\mathrm{OH})_{2}, \mathrm{SiO}_{2}, \mathrm{Al}_{2} \mathrm{O}_{3}, \mathrm{AlO}(\mathrm{OH})\right.$, $\mathrm{MgO}$ and $\mathrm{MoO}_{3}$ ]. All obtained intensities were identified by JCPDS cards [071-1126 for $\mathrm{Al}_{2} \mathrm{O}_{3}, 086-1628$ for $\mathrm{SiO}_{2}$, 089-5108 for $\mathrm{MoO}_{3}, 089-4248$ for $\mathrm{MgO}, 083-0114$ for $\mathrm{Mg}(\mathrm{OH})_{2}$ and 074-1879 for $\left.\mathrm{AlO}(\mathrm{OH})\right]$. However, intensities of some peaks decreased with activation time, while some peaks are broadened which indicates that processes of crystal lattice destruction and amorphization have started (Fig. 1). Some $\mathrm{AlO}(\mathrm{OH}), \mathrm{MoO}_{3}$ and $\mathrm{Mg}(\mathrm{OH})_{2}$ peaks may have not completely disappeared during activation process, but their concentration in the mixtures is too low to be detected using this technique. Although no new phases have been detected, our assumption is that the formation of new phases may have started, but those peaks are probably overlapped with $\mathrm{SiO}_{2}$ peaks that are broadened. Due to great hardness of $\mathrm{SiO}_{2}$ powder (crystal lattice energy is $13.125 \mathrm{~kJ} \mathrm{~mol}^{-1}$ ), minor changes are notices within.

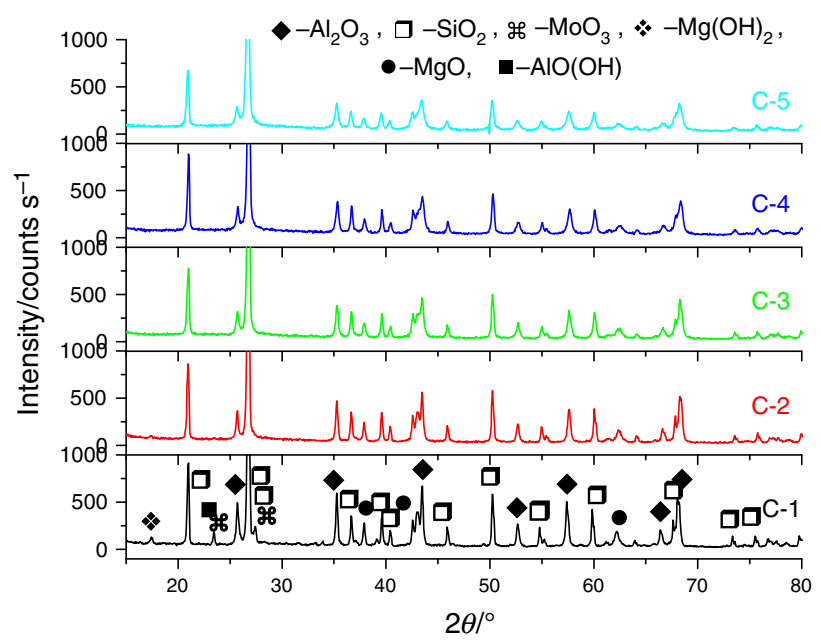

Fig. 1 XRD patterns of non-activated and mixtures activated 10-160 min 
Particle size analysis, presented in Fig. 2, showed that average particle size $d(0.5)$, for non-activated mixture (C-1) is around $6 \mu \mathrm{m}$, while the value decreased with the increase in activation time (C-2). An exception from this behavior is noticed within powder $\mathrm{C}-3$, where the particle size value is larger (around 9 microns). This type of behavior is consequence of agglomerates formation as a tendency of activated powder to decrease its surface energies. Average particle size for mixtures activated for 80 and $160 \mathrm{~min}$ is less than $5 \mu \mathrm{m}$. This is in accordance with XRD results, where destruction of crystal lattice was noticed as well as peak intensities decreasing as a function of prolonged activation time.

Figure 3 represents SEM micrographs of non-activated mixture and mixtures activated for 10, 40, 80 and $160 \mathrm{~min}$. Initial non-activated mixture is a submicron powder composed of large number of particles various in shape and size. Attrition is noticed within powder activated $10 \mathrm{~min}$. SEM C-3 represents agglomerates 5 micron in size covered by smaller particles, more uniform and regularly shaped. Micrographs (d) and (e) indicate at further attrition of agglomerates that were formed during prolonged mechanical activation.

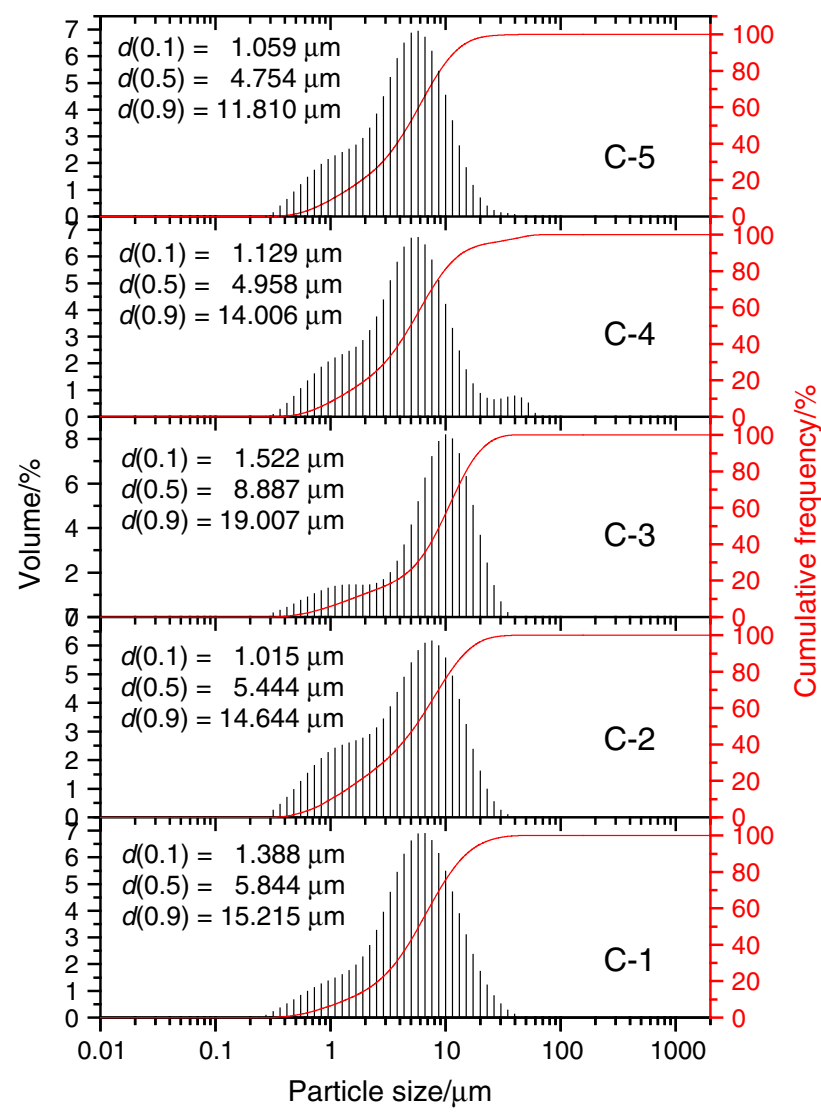

Fig. 2 Particle size analysis of mixtures non-activated and activated for $10-160 \mathrm{~min}$
The milling process produces significant changes in the DTA-TG curves. Curves of non-activated and mixtures activated $10-160 \mathrm{~min}$, with $10{ }^{\circ} \mathrm{C} \mathrm{min}^{-1}$ heating rate, are shown in Figs. 4 and 5. All samples have well-defined DTA peaks. The first one is a strong endothermic peak at around $100{ }^{\circ} \mathrm{C}$, which belongs to humidity evaporation. Second is a weak endothermic peak at around $400{ }^{\circ} \mathrm{C}$ corresponding to the dehydroxylation of $\mathrm{Al}_{2} \mathrm{O}_{3}$-based compounds [12]. A second important endothermic peak is observed in $\mathrm{C}$ - 1 , centered at $574{ }^{\circ} \mathrm{C}$, corresponding to the structural $\alpha \rightarrow \beta$ phase transition in crystalline $\mathrm{SiO}_{2}$ [17]. This peak has a tendency to decrease its area when milling. In $\mathrm{C}-5$, it becomes reduced to a small hump. Afterward, a small exothermic effect at $1045{ }^{\circ} \mathrm{C}$ appears in the mixture without treatment. This peak is due to the transformation of the non-crystalline structure of the $\mathrm{SiO}_{2}$-based compounds into a spinel or premullite phase [16]. This peak gradually shifts to lower temperatures with the increase in the grinding time. The fact that the premullite phase does not appear as a crystalline phase using XRD must be taken into account. Furthermore, exothermic peak centered at $1170{ }^{\circ} \mathrm{C}$ for $\mathrm{C}-1$ and shifted to lower temperatures for activated samples (around $1120{ }^{\circ} \mathrm{C}$ ) could be attributed to mullite formation [11]. A reduction in the temperature can be observed for all activated samples. This is due to the reduction in the energy necessary to destroy the crystalline structure of the system. The energy supplied by the planetary mill causes structural disorder, through the distortion or breakage of the crystalline structure. This is evident from the reduction in the intensities of XRD peaks.

Within the range $1150-1400{ }^{\circ} \mathrm{C}$ (Fig. 4b), a series of exothermic effects were detected. De Aza et al. [18] using a high-sensitivity equipment found two exothermic peaks at 1275 and $1357{ }^{\circ} \mathrm{C}$, both corresponding to the formation of cordierite. In our case, the first peak can be detected in the $\mathrm{C}$-1 sample centered at $1260{ }^{\circ} \mathrm{C}$ and shifted to lower temperatures (around $1200{ }^{\circ} \mathrm{C}$ ) when milling, having a tendency to increase the intensity, corresponding to $\mu$ cordierite formation. In the activated samples, the exothermic peak for $\mathrm{C}-1$ at $1328{ }^{\circ} \mathrm{C}$ which shifts to temperatures of about $1290{ }^{\circ} \mathrm{C}$ is assigned to the formation of $\alpha$-cordierite [19].

The analysis of the TG curves (Fig. 5) confirms the behaviors observed by DTA since the dehydroxylation is accompanied by the corresponding mass losses.

The C-1 sample presents three mass loss steps well defined at 200, 400 and $1200{ }^{\circ} \mathrm{C}$, which are in accordance with the DTA peaks described, corresponding to water evaporation, dehydroxylation process and $\mathrm{MoO}_{3}$ evaporation [20], respectively.

Kissinger's equation [21] was employed to calculate apparent activation energies of various processes that occur within the system while heating: 

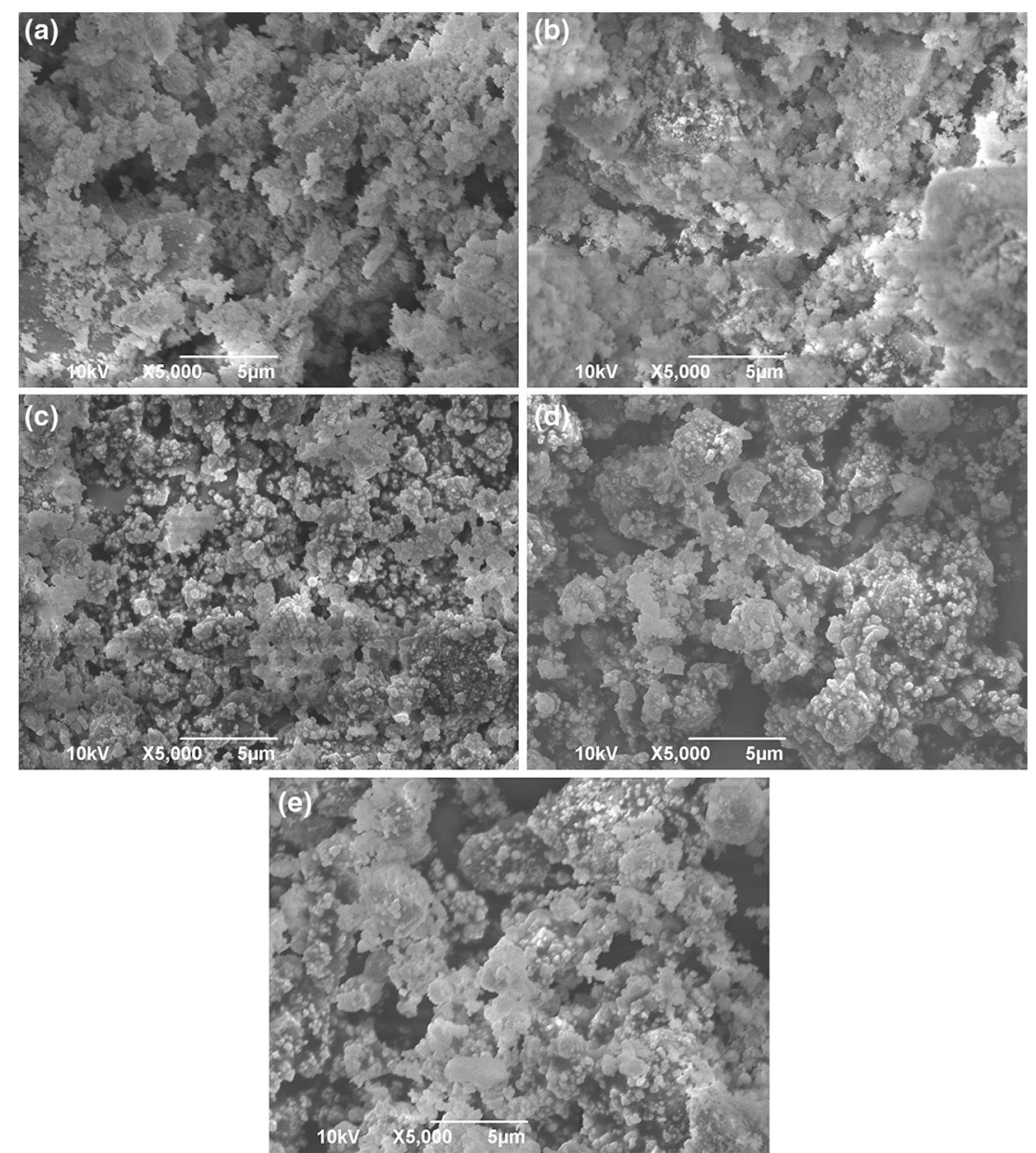

Fig. 3 SEM micrographs of samples a C-1, b C-2, c C-3, d C-4 and e C-5

$\ln \left(\frac{\beta}{T_{\mathrm{p}}^{2}}\right)=C-\frac{E_{\mathrm{a}}}{R} \cdot\left(\frac{1}{T_{\mathrm{p}}}\right)$

where $\beta$ is a constant heating rate $\left(5,10,20\right.$ and $\left.30^{\circ} \mathrm{C} \min ^{-1}\right)$, $T_{\mathrm{p}}$ is the maximal absolute temperature at which the reaction peak/maximum occurs, $R$ represents an ideal gas constant $8.314 \mathrm{~J} \mathrm{~mol}^{-1} \mathrm{~K}^{-1}, \mathrm{C}$ is a constant and $E_{\mathrm{a}}$ is the activation energy. Values of activation energies are given in Table 1.

The first peak at $1045{ }^{\circ} \mathrm{C}$ for $\mathrm{C}-1$ and lower for activated samples corresponds to the transformation of the noncrystalline structure of the $\mathrm{SiO}_{2}$-based compounds into a spinel or premullite phase. The second peak at $1260{ }^{\circ} \mathrm{C}$ for $\mathrm{C}-1$ and lower for treated samples is assigned to cordierite formation. And the third peak centered at $1325{ }^{\circ} \mathrm{C}$ for nonactivated sample and lower for activated samples is due to $\alpha$-cordierite formation.

Table 1 shows apparent activation energies for various processes. It is clearly indicated that with prolonged milling time, obtained values decrease. Mechanical energy introduced into the system during the mechanical treatment lowers energy necessary for enactment of appropriate processes. For example, energy necessary for cordierite formation is $212 \mathrm{~kJ} \mathrm{~mol}^{-1}$ for non-activated sample and decreases to $70 \mathrm{~kJ} \mathrm{~mol}^{-1}$ for the longest activated sample. Powder become more reactive due to the increase in specific surface area and number of contacts between particles which lead to the decrease in energy needed for reactions.

An exception to this tendency is noticed for $\alpha$-cordierite formation. The highest value of activation energy is observed for sample activated $40 \mathrm{~min}$, which could be correlated with existing agglomerates. In Fig. 2, distribution of sample C-3 shows the value $d(0.9)=19 \mu \mathrm{m}$. Reaction of such agglomerated powder is significantly more difficult owing to less number of contacts between particles, which leads to the increase in energy necessary for this mentioned process. 

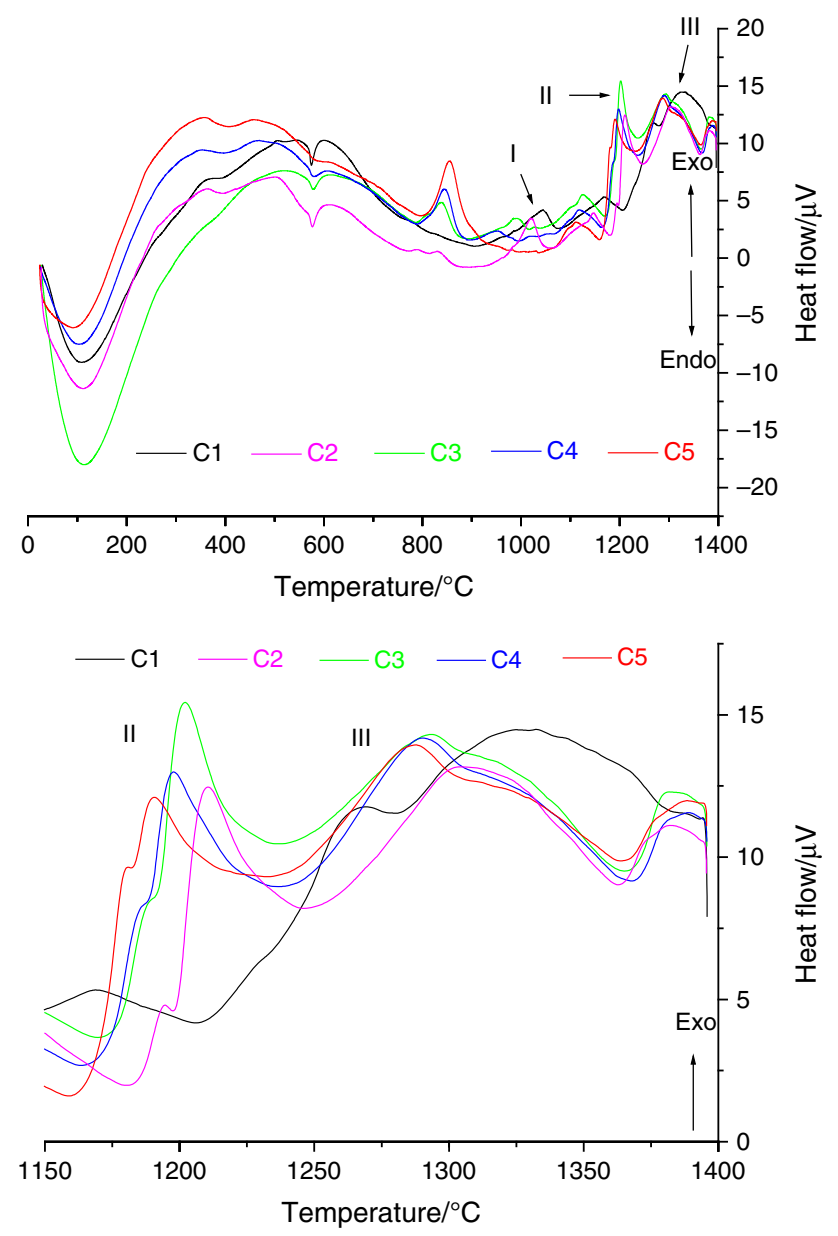

Fig. 4 a DTA curves of non-activated and mixtures activated 10-160 min, with $10{ }^{\circ} \mathrm{C} \min ^{-1}$ heating rate b DTA curves of nonactivated and mixtures activated $10-160 \mathrm{~min}$ with enlarged temperature interval $1150-1400{ }^{\circ} \mathrm{C}$, with $10^{\circ} \mathrm{C} \mathrm{min}^{-1}$ heating rate

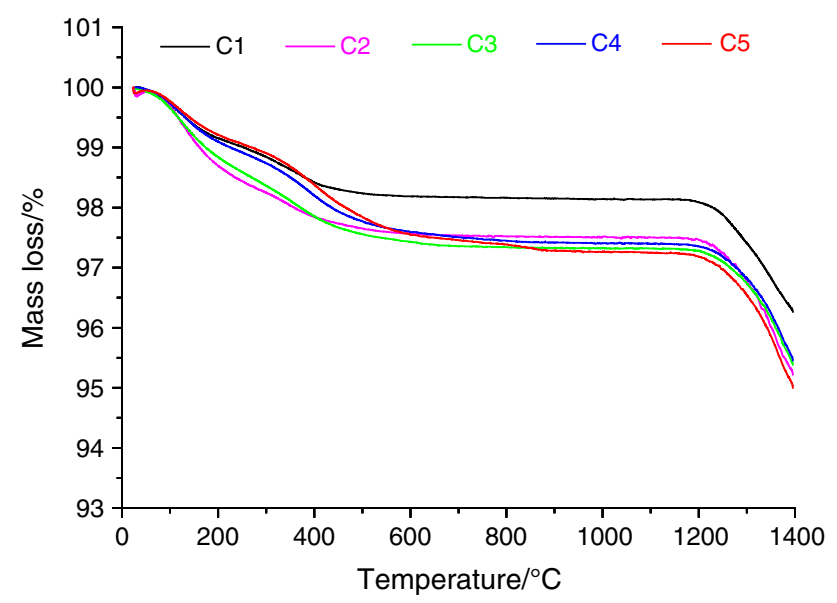

Fig. 5 TG curves of non-activated and mixtures activated 10-160 $\min$
Table 1 Activation energies for various processes obtained by Kissinger's equation

\begin{tabular}{|c|c|c|c|c|c|}
\hline \multirow[t]{2}{*}{ Peak } & \multicolumn{5}{|c|}{$E_{\mathrm{a}} / \mathrm{kJ} \mathrm{mol}^{-1}$} \\
\hline & C-1 & $\mathrm{C}-2$ & $\mathrm{C}-3$ & C-4 & C-5 \\
\hline I & 337.815 & 245.295 & 243.917 & 215.316 & - \\
\hline II & 211.903 & 166.084 & 158.488 & 77.154 & 70.096 \\
\hline III & 370.506 & 672.146 & 1562.212 & 650.109 & 616.369 \\
\hline
\end{tabular}

Figure 6 shows XRD patterns of activated and sintered samples. As it can be seen from presented diffractograms, single-phase system was not achieved. Cordierite is a major occurred phase along with minor share of $\mathrm{MgAl}_{2} \mathrm{O}_{4}, \mathrm{SiO}_{2}$ and $\mathrm{Al}_{2} \mathrm{O}_{3}$. Formation of spinel $\mathrm{MgAl}_{2} \mathrm{O}_{4}$ is caused by the presence of $\mathrm{MgO}$ and $\mathrm{Al}_{2} \mathrm{O}_{3}$ agglomerates in starting powder mixtures, incurred during the mechanical treatment. Furthermore, should be noted that few peaks of quartz is superimposed to the intensive peaks of cordierite so identification is not trivial and easy. Sharper and intensive peaks of cordierite indicate that reaction sintering along with crystallization take place during heating treatment. Presence of other phases indicates that reaction is not completed yet.

Figure 6 presents changes in microstructure of activated samples sintered at $1300{ }^{\circ} \mathrm{C}$ for $2 \mathrm{~h}$. As it can be noticed, all samples show very high porosity, which is in correlation with very low values of relative densities (shown in Table 2, from 73 to $\sim 77 \%$ TD). Low densities about $77 \%$ usually characterize cordierite ceramic [22]. Even cordierite

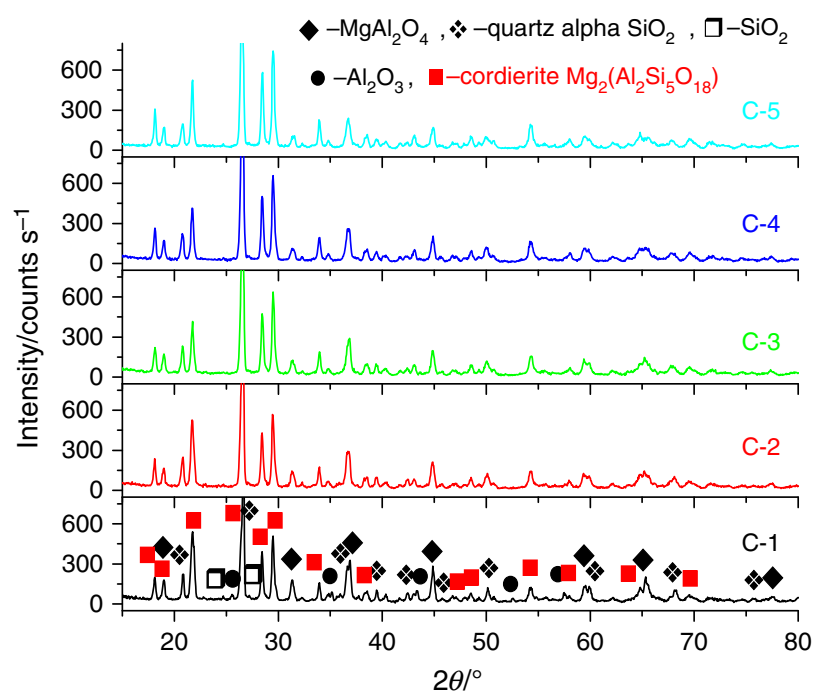

Fig. $6 \mathrm{XRD}$ patterns of non-activated and activated mixtures sintered at $1300{ }^{\circ} \mathrm{C}$ for $2 \mathrm{~h}$ 
Table 2 Densities of samples sintered at $1300{ }^{\circ} \mathrm{C}$ for $2 \mathrm{~h}$

\begin{tabular}{ll}
\hline sample & $\rho_{\mathrm{S}} / \% \mathrm{TD}$ \\
\hline $\mathrm{C}-1$ & 74.42 \\
$\mathrm{C}-2$ & 76.57 \\
$\mathrm{C}-3$ & 76.77 \\
$\mathrm{C}-4$ & 75.49 \\
$\mathrm{C}-5$ & 73.15
\end{tabular}

$T D$ theoretical density $\left(2.51 \mathrm{~g} \mathrm{~cm}^{-3}\right)$

obtained using other synthesis methods, such as obtaining from preceramic polymers, does not reach higher densities than $80 \%$ of TD [10]. At micrograph of samples activated for 40 and $80 \mathrm{~min}$, note the large compact areas which are consequence of sintering within the agglomerate of starting powders. Present open porosity along with low-density values indicates first or early medium sintering stage for these samples (Fig. 7).

\section{Conclusions}

Simultaneous action of effects, mechanical treatment as well as additives addition were investigated through monitoring reaction kinetics of mechanically activated cordierite-based ceramics, doped with $\mathrm{MoO}_{3}$, via DTA.

XRD results indicate no new phase formation although intensive decrease in peak's intensities along with amorphization and peak broadening has been noticed. Particle size analysis indicates the attrition of starting powders. The increase in particle size is observed for sample activated $40 \mathrm{~min}$, indicating the presence of agglomerates, followed by SEM micrographs. DTA has given us characteristic temperatures for various well-described processes occurring in the system during heating up to $1400{ }^{\circ} \mathrm{C}$. Based on Kissinger's equation, activation energies for spinel or premullite phase formation, cordierite and $\alpha$-cordierite formation were calculated. Decrease in activation energy for the first process from 338 to $215 \mathrm{~kJ} \mathrm{~mol}^{-1}$ and for the
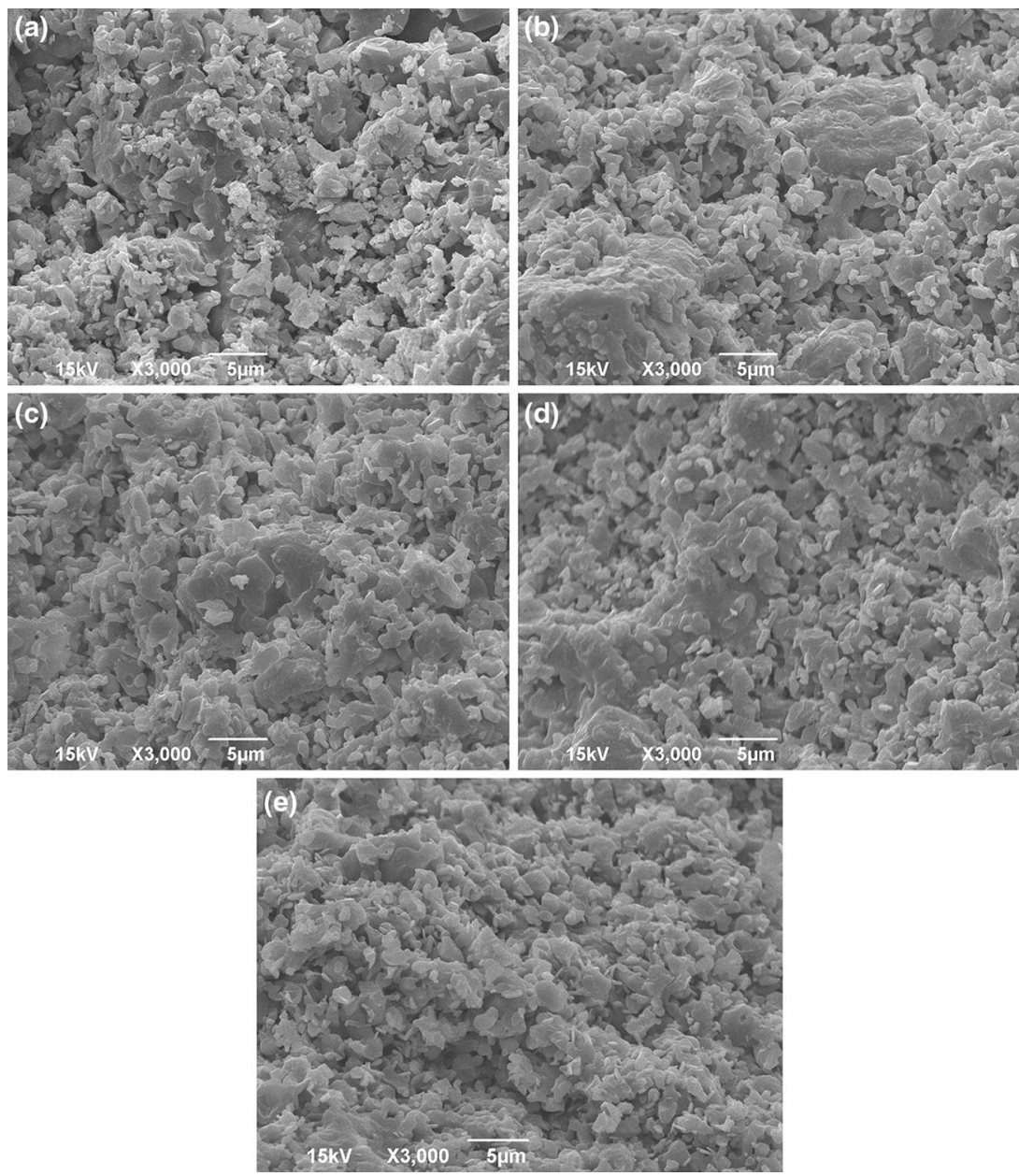

Fig. 7 SEM micrographs of samples a C-1, b C-2, c C-3, d C-4 and e C-5, sintered at $1300{ }^{\circ} \mathrm{C}$ for $2 \mathrm{~h}$ 
second one from 212 to $70 \mathrm{~kJ} \mathrm{~mol}^{-1}$ is correlated with the increase in powder reactivity which is caused by introduced mechanical energy. An exception for process of $\alpha$ cordierite formation was attributed to agglomerate existence. Comparing to the literature data, it was established that mechanical activation with $\mathrm{MoO}_{3}$ addition leads to the decrease in sintering temperature for more than $100{ }^{\circ} \mathrm{C}$.

Thermal treatment did not lead to single-phase formation. Beside cordierite as a major phase, XRD patterns showed minor share of $\mathrm{MgAl}_{2} \mathrm{O}_{4}, \mathrm{SiO}_{2}$ and $\mathrm{Al}_{2} \mathrm{O}_{3}$ phases. Densities exceed $70 \%$ of TD, which is common for this type of ceramic material.

Acknowledgements This research was performed within the project 172057, funded by the Ministry for education, science and research development of the Republic of Serbia and project F-7/II funded by the Serbian Academy of Sciences and Arts.

\section{References}

1. Marzieh K, Touradj E. Effect of mechanical activation and microwave sintering on crystallization and mechanical strength of cordierite nanograins. Ceram Int. 2015;41:2342-7.

2. Jankovic-Castvan I, Lazarevic S, Tanaskovic D, Orlovic A, Petrovic R, Dj Janackovic. Phase transformation in cordierite gel synthesized by non-hydrolitic Sol-Gel route. Ceram Int. 2007;33: 1263-8.

3. Drummond $\mathrm{CH}$. Glass formation and crystallization in high temperature glass ceramics and $\mathrm{Si}_{3} \mathrm{~N}_{4}$. J Non-Cryst Solids. 1990; 123:114-28.

4. Warsworth I, Stevens R. The influence of whisker dimensions on the mechanical properties of cordierite/SiC whisker composites. J Eur Ceram Soc. 1992;9:153-63.

5. Pinero M, Atik M, Zarzycki J. Cordierite- $\mathrm{ZrO}_{2}$ and cordierite$\mathrm{Al}_{2} \mathrm{O}_{3}$ composites obtained by sonocatalytic methods. J NonCryst Solids. 1992;147-148:523-31.

6. Kervadec D, Coster M, Chermant JL. Morphology of magnesium lithium aluminum silicate matrix reinforced by silicon carbide fibers during high temperature tests. Mater Res Bull. 1992;27: 967-74.

7. Zobina LD, Semchenko GD. Belik YaG. Synthesis of cordierite and the technology of cordierite-containing articles. Refractories. $1983 ; 24: 72-5$.
8. Fotoohi B, Blackburn S. Effects of mechanochemical processing and doping of functional oxides on phase development in synthesis of cordierite. J Eur Ceram Soc. 2012;32:2267-72.

9. Luo L, Zhou H, Xu C. Microstructural development on sol-gel derived cordierite ceramics doped $\mathrm{B}_{2} \mathrm{O}_{3}$ and $\mathrm{P}_{2} \mathrm{O}_{5}$. Mater Sci Eng B. 2003;99:348-51.

10. Parcianello G, Bernardo E, Colombo P. Cordierite ceramics from silicone resins containing nano-sized oxide particle fillers. Ceram Int. 2013;39:8893-9.

11. Neto JBR, Moreno R. Effect of mechanical activation on the rheology and casting performance of kaolin/talc/alumina suspensions for manufacturing dense cordierite bodies. Appl Clay Sci. 2008;38:209-18.

12. Tamborenea S, Mazzoni AD, Aglietti EF. Mechanochemical activation of minerals on the cordierite synthesis. Thermochim Acta. 2004;411:219-24.

13. Koc S, Toplan N, Yildiz K, Toplan HO. Effects of mechanical activation on the non-isothermal kinetics of mullite formation from kaolinite. J Therm Anal Calorim. 2011;103:791-6.

14. Farhanchi M, Neysari M, Barenji RV, Heidarzadeh A, Mousavian RT. Mechanical activation process for self-propagation high temperature synthesis of ceramic-based composites. J Therm Anal Calorim. 2015;122:123-33.

15. Obradović N, Đorđević N, Peleš A, Filipović S, Mitrić M, Pavlović VB. The influence of compaction pressure on the density and electrical properties of cordierite-based ceramics. Sci Sinter. 2015;47:15-22.

16. Yalamac E, Akkurt S. Additive and intensive grinding effects on the synthesis of cordierite. Ceram Int. 2006;32:825-32.

17. Tucker MG, Keene DA, Dove MT. A detailed structural characterization of quartz on heating through the $\alpha-\beta$ phase transition. Mineral Mag. 2001;65:489-507.

18. De Aza S, Monteros E. Mecanismo de la formación de cordierita en cuerpos cerámicos. Bol Soc Esp Ceram Vidr. 1972;11:315-21.

19. Kirsever D, Karakus N, Toplan N, Toplan HO. The cordierite formation in mechanically activated talc-kaoline-alumina-basaltquartz ceramic system. Acta Phys Polonica A. 2014;127:1042-4.

20. Chychko A, Teng L, Seetharaman $\mathrm{S}$. $\mathrm{MoO}_{3}$ evaporation studies from binary systems towards choice of Mo precursors in EAF. Steel Res Int. 2010;81:783-91.

21. Kissinger HE. Reaction kinetics in differential thermal analysis. Anal Chem. 1957;29:1702-6.

22. Obradović N, Đorđević N, Filipović S, Nikolić N, Kosanović D, Mitrić M, Marković S, Pavlović V. Influence of mechanical activation on the sintering of cordierite ceramics in the presence of $\mathrm{Bi}_{2} \mathrm{O}_{3}$ as a functional aditive. Powder Technol. 2012;218: 157-61. 